\title{
Novel donor-acceptor systems bearing an isoxazol-5-one core
}

\author{
Mariusz Tasior, Piotr Gajewski, Olena Vakuliuk, and Daniel T. Gryko* \\ Institute of Organic Chemistry, Polish Academy of Sciences, 44/52 Kasprzaka, \\ 01-224 Warsaw, Poland \\ Email: daniel.gryko@icho.edu.pl
}

Dedicated to Prof. Zbigniew Czarnocki on the occasion of his $66^{\text {th }}$ anniversary

Received 04-18-2020

Accepted 07-17-2020

Published on line 07-29-2020

\section{Abstract}

The synthesis of previously unknown esters of 4-(arylmethylene)-5-oxo-4,5-dihydroisoxazole-3-carboxylic acids from aromatic aldehydes, hydroxylamine- $O$-sulfonic acid and diethyl acetylenedicarboxylate via a two-step one-pot reaction is presented. The mechanism of the reaction is discussed, and optimization is carried out. The scope and limitations of this multicomponent reaction are described.

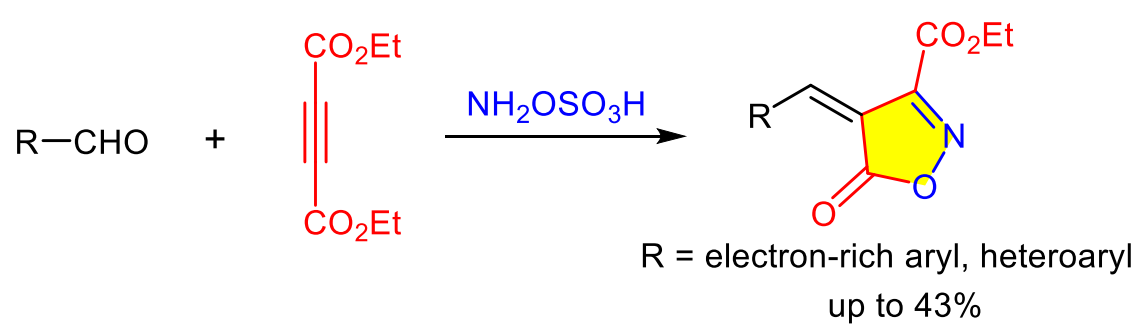

Keywords: isoxazol-5-ones, push-pull chromophores, multicomponent reactions, UV/vis absorption, tandem reactions 


\section{Introduction}

The isoxazol-5(4H)-one moiety ${ }^{1}$ is an important structural motif, present in the number of biologically active compounds, ${ }^{2-5}$ natural products ${ }^{6,7}$ and advanced materials. ${ }^{8-10}$ By 1897 , Schiff and Betti had already discovered that 4-arylmethylene-isoxazol-5-ones could be prepared by treating acetoacetic ester oxime with various aromatic aldehydes. ${ }^{11}$ Later, Minnuni and co-workers, ${ }^{12}$ as well as Donleavy et al., ${ }^{13}$ obtained the same products from oximes and ethyl acetoacetate. Unsubstituted isoxazolin-5-one was synthesized for the first time by De Sarlo and co-workers from hydroxylamine and ethyl propiolate. ${ }^{14}$

Nowadays, molecules bearing the isoxazol-5-one core can be prepared via a number of synthetic strategies, often taking the advantage of one-pot protocols. Namely, the multicomponent reactions between ethyl acetoacetate, hydroxylamine and aromatic aldehydes afford the corresponding isoxazol-5-ones in the presence of acid or base, in high yields. ${ }^{15-17}$ It is noteworthy that methods leading to products bearing an ester group at position 3 are essentially unknown even though the role of this synthetic handle cannot be underestimated. Thus, there is still a strong need for a new synthetic tool in the preparation of isoxazol-5ones, allowing for their convenient post-functionalization.

\section{Results and Discussion}

During a project aiming at the synthesis of pentasubstituted pyridines, we unexpectedly discovered a new multicomponent reaction leading to compounds bearing the isoxazol-5-one skeleton. In 2011, Sun et al. developed the synthesis of tetraesters of $N$-substituted-1,4-dihydropyridine-2,3,5,6-tetracarboxylic acids via condensation of diethyl acetylenedicarboxylate with aromatic aldehydes and aryl hydroxylamines. ${ }^{18}$ Targeting the $\mathrm{N}$-unsubstituted analogue, we decided to modify the original procedure by using a hydroxylamine derivative bearing a good leaving group, that after elimination can directly give an aromatized product. Our first choice was hydroxylamine-O-sulfonic acid due to its accessibility. Low substrate conversion was observed when 4-methoxybenzaldehyde (1) was treated at room temperature with hydroxylamine-O-sulfonic acid and diethyl acetylenedicarboxylate (2) in EtOH (Scheme 1).

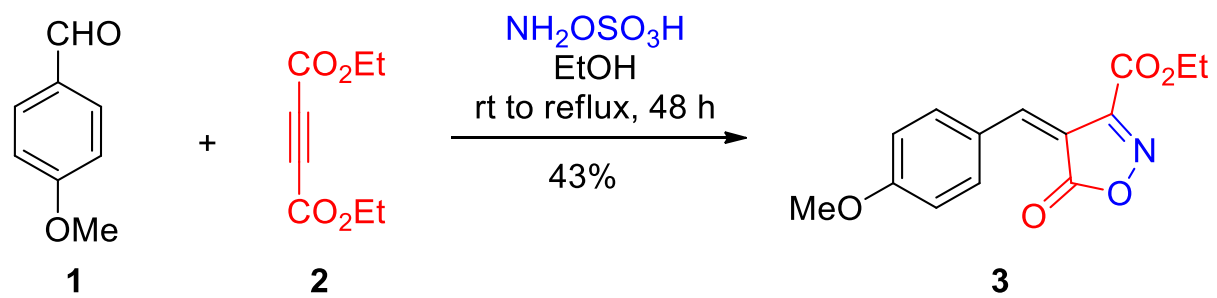

Scheme 1. Synthesis of isoxazol-5-one 3.

Nevertheless, when the reaction was heated to reflux, the colorless solution changed to deep orange, and after cooling, fine yellow-orange needles of an analytically pure product were formed (Scheme 1). NMR and mass spectrometry analyses excluded the formation of the expected product, suggesting at the same time the formation of a heterocyclic 5-membered ring. To get further insights into the structure of this puzzling product, crystals suitable for X-ray crystallography were obtained by vapor diffusion of hexane into a DCM solution of the compound. X-Ray crystallography supported the presence of the 5-ring and the structure 
assigned to compound 3. The molecule is almost planar with the mean angle between both rings being $177.3^{\circ}$ (Figure 1).

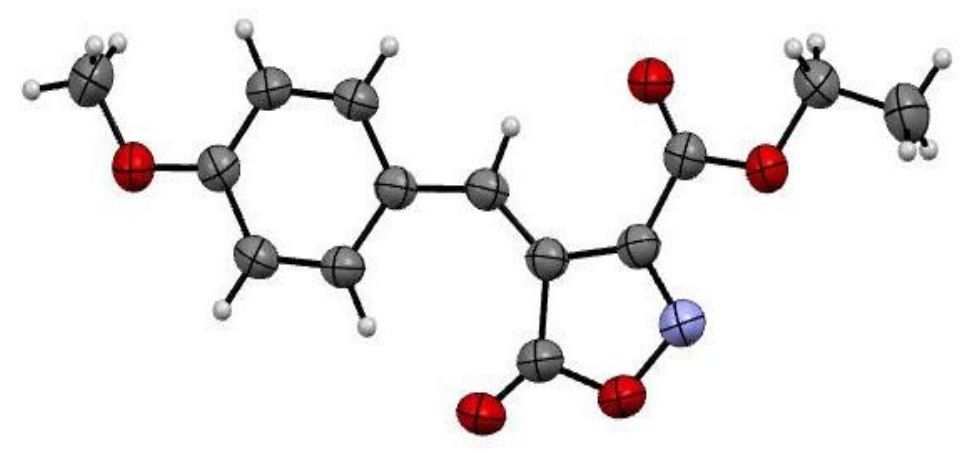

Figure 1. ORTEP X-ray structure of 3.

A brief study of the literature revealed that such isoxazol-5-ones bearing an ester group at position 3 were described only once before, in a Japanese patent from the 1990s. ${ }^{19}$ As the patent described photochemically active materials, we become interested in whether the obtained product exhibits any interesting photophysical properties. Compound $\mathbf{3}$ has a very intense yellow-orange color, which can be explained by its push-pull structure which resembles products of condensation of 4-methoxybenzaldehyde with barbituric acid. ${ }^{20}$ The chromophore comprises both the benzene ring and the five-membered isoxazolone moiety and slightly resembles that of green fluorescent proteins. ${ }^{21}$

Table 1. Optimization of synthesis of isoxazol-5-one 3 from hydroxylamine-O-sulfonic acid

\begin{tabular}{ccccc}
\hline Entry & Solvent & $1^{\text {st }}$ step $^{\mathrm{a}}(\mathrm{h})$ & $2^{\text {nd }}$ step $^{\mathrm{b}}(\mathrm{h})$ & Yield $^{(\%)}$ \\
\hline 1 & EtOH & 48 & 1.5 & 43 \\
2 & EtOH & 48 & 1.5 & $1.5^{\mathrm{c}}$ \\
3 & $\mathrm{EtOH}$ & 0 & 6.5 & 29 \\
4 & $\mathrm{EtOH}$ & 18 & 6 & 43 \\
5 & $\mathrm{EtOH}$ & 0 & 26 & 34 \\
6 & $\mathrm{THF}$ & 0 & 6.5 & 26 \\
7 & $\mathrm{MeCN}$ & 0 & 6.5 & 24 \\
8 & $\mathrm{AcOH}$ & 0 & 4.5 & traces $^{\mathrm{d}}$ \\
9 & $\mathrm{EtOH}$ & 0 & 4.5 & traces $^{\mathrm{d}}$ \\
10 & $\mathrm{EtOH}$ & 0 & 4.5 & traces $^{\mathrm{e}}$ \\
\hline
\end{tabular}

a performed at the room temperature; ${ }^{b}$ performed at reflux;

c reaction with hydroxylamine hydrochloride; d reaction catalyzed by $\mathrm{Fe}(\mathrm{OTf})_{3}$ (3 mol\%); e reaction catalyzed by $\mathrm{Cu}(\mathrm{OTf})_{2}(3 \mathrm{~mol} \%)$.

Since the yield of the product $\mathbf{3}$ was moderate, we began the optimization process, testing also another hydroxylamine source, hydroxylamine hydrochloride (Table 1). Surprisingly, the yield of the product $\mathbf{3}$ was nearly 30 times lower than in the case of hydroxylamine-O-sulfonic acid (Table 1, entry 2), for reasons we do not fully understand. We thought that in this case the product could remain in solution as the corresponding 
hydrochloride. However, treatment of the reaction mixture with an excess of triethylamine brought no improvement. We also tried to shorten the reaction time, however, stirring at room temperature for at least $16 \mathrm{~h}$ was required to reach a satisfactory yield of product 3 (Table 1, entries 3-5). The exploration of other solvents was limited due to the poor solubility of hydroxylamine-O-sulfonic acid in non-polar media. Solvents other than ethanol did not afford any particular benefit. On the contrary, the obtained product 3 did not precipitate from the reaction mixture, complicating the product purification (Table 1, entries 6-8). The addition of catalytic amounts of transition metal salts (Table 1, entries 9-10) also did not improve the yields of 3.

Table 2. Scope of the investigated reaction

Aldehyde

Both 4-dimethylaminobenzaldehyde (4) and pyrrole-2-carbaldehyde (5) led to the expected products 6 and 7 in low yields, but 2-hydroxybenzaldehyde failed to give the desired heterocycle. Subsequently, we examined electron-poor aldehydes such as pyridine-2-carboxaldehyde, 4-formylbenzonitrile and pentafluorobenzaldehyde. Surprisingly, none of these reagents allowed to obtain the expected isoxazolones, which forced us to a more detailed analysis of the composition of the reaction mixtures. Therefore, after crystallization of compound 3, we submitted the filtrate to chromatographic purification to identify the structure and the distribution of the side products. It is noteworthy that esters of acetylenedicarboxylic acid, owing to their high reactivity, are known to undergo numerous multicomponent reactions. For example, the reaction between diethyl acetylenedicarboxylate and aromatic or aliphatic amines leads to, depending on the conditions, enaminoesters, aminomaleimides, ${ }^{22}$ 2-pyridones, ${ }^{23}$ substituted pyrroles, ${ }^{24}$ etc. In the presence of amine and aromatic aldehyde, diethyl acetylenedicarboxylate forms products such as 3-amino 1,5-dihydro-2 $\mathrm{H}$-pyrrol-2ones and 3-hydroxy-1,5-dihydro-2H-pyrrol-2-ones. ${ }^{25}$ In the above mentioned reaction leading to compound 3, besides non-reacted 4-methoxybenzaldehyde (20\%), we isolated 4-methoxybenzonitrile (10\% yield) as a side product resulting from oxime formation followed by elimination of sulfuric acid. Taking into account the complexity of the discussed process, it is therefore easier to understand the lack of expected product in reactions with electron-poor aldehydes, since their higher reactivity versus nucleophiles might easily switch the reaction pathway. We also attempted to synthesize the desired heterocycles in a step-by-step manner but the experiments with an aqueous solution of formaldehyde failed to give ethyl 5-oxo-4,5-dihydroisoxazole-3carboxylate, which we planned to transform into arylmethylene-derivative by condensation with aldehyde in 
presence of base. Overall, despite the limited applicability, the cheap starting materials and simple reaction work-up make our method an attractive way of the preparation of arylmethyleneisoxazoles.

These new dyes belong to the class of dipolar chromophores (push-pull chromophores) with an aromatic ring acting as donor and the isoxazolone scaffold as electron-acceptor. The presence of the electronwithdrawing $\mathrm{CO}_{2} \mathrm{Et}$ group increases the electron-accepting properties of the heterocycle, resulting in a bathochromic shift of absorption maxima of dyes 3, 6 and 7 compared to analogous isoxazolones lacking this group. ${ }^{19}$ The absorption maxima of isoxazolones $\mathbf{6}$ and $\mathbf{7}$ is bathochromically shifted in comparison to that of compound 3, which can be explained by more pronounced electron-donating character of the aryl substituents. ${ }^{26-29}$ For all tested compounds 3, 6 and 7 no fluorescence was detected, which is probably caused by thermal relaxation via the rotation at a methine bridge.

We believe that from a mechanistic point of view this reaction proceeds via Michael addition of hydroxylamine to diethyl acetylenedicarboxylate, with formation of enamine, which subsequently reacts with aromatic aldehyde. The resulting oxime- $O$-sulfonic acids tend to eliminate sulfur trioxide above room temperature, ${ }^{30}$ and then the transesterification reaction leads to the final product.

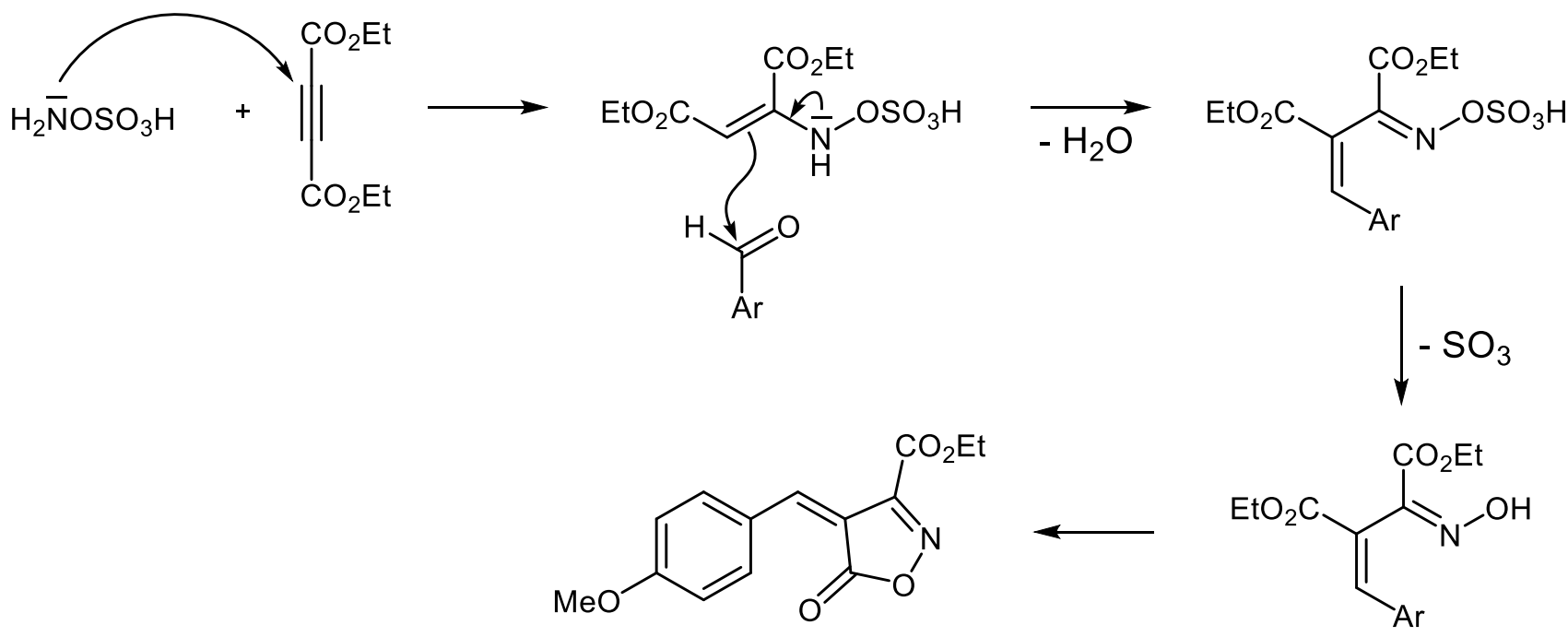

Scheme 2. Plausible mechanism of formation of esters of 4-(arylmethylene)-5-oxo-4,5-dihydroisoxazole-3carboxylic acids.

\section{Conclusions}

We have developed a new method for the preparation of isoxazole-5-ones in one-pot two-step protocol, from electron-rich aromatic aldehydes, diethyl acetylenedicarboxylate and hydroxylamine-O-sulfonic acid. The reaction is straightforward, giving rise to a new type of dye strongly absorbing green light and possessing ester group as a convenient synthetic handle. 


\section{Experimental Section}

General. ${ }^{1} \mathrm{H}$ and ${ }^{13} \mathrm{C}$ NMR were recorded on a Varian VNMRS $500\left({ }^{1} \mathrm{H}: 500 \mathrm{MHz},{ }^{13} \mathrm{C}: 126 \mathrm{MHz}\right)$ The chemical shifts $(\delta)$ and coupling constants $(J)$ are expressed in ppm and Hertz, respectively. UV-vis spectra were recorded on a Perkin-Elmer Lambda 25 spectrophotometer.

(Z)-Ethyl 4-(4-methoxybenzylidene)-5-oxo-4,5-dihydroisoxazole-3-carboxylate (3) (Typical procedure). To a stirred mixture of hydroxylamine-O-sulfonic acid $(0.46 \mathrm{~g}, 4.11 \mathrm{mmol})$ in ethanol $(10 \mathrm{~mL})$, under nitrogen, diethyl acetylenedicarboxylate $(0.7 \mathrm{~mL}, 4.11 \mathrm{mmol})$ was added. After 10 minutes of vigorous stirring to the solution was added a mixture of 4-methoxybenzaldehyde ( $0.5 \mathrm{~mL}, 4.11 \mathrm{mmol})$ in ethanol (4 mL). The reaction mixture was stirred at $\mathrm{rt}$ overnight and then heated to reflux for $4 \mathrm{~h}$. After $24 \mathrm{~h}$ in rt, the precipitate was filtered, washed with ice-cold ethanol and dried to give the analytically pure title compound $3(0.41 \mathrm{~g}, 43 \%)$ as yellow-orange needles. Mp 112-115 ${ }^{\circ} \mathrm{C}$. IR (KBr): $V_{\max } 1715,1605,1436,1257,1207,1149,901,752 \mathrm{~cm}^{-1} .{ }^{1} \mathrm{H}$ NMR $\left(500 \mathrm{MHz}, \mathrm{DMSO}-d_{6}\right) \delta_{\mathrm{H}} 8.51(\mathrm{~d}, J 9.0 \mathrm{~Hz}, 2 \mathrm{H}), 8.48(\mathrm{~s}, 1 \mathrm{H}), 7.19(\mathrm{~d}, J 9.0 \mathrm{~Hz}, 2 \mathrm{H}), 4.42(\mathrm{q}, J 7.1 \mathrm{~Hz}, 2 \mathrm{H})$, $3.93(\mathrm{~s}, 3 \mathrm{H}), 1.36$ (t, J $7.1 \mathrm{~Hz}, 3 \mathrm{H}) .{ }^{13} \mathrm{C}$ NMR (126 MHz, DMSO- $\left.d_{6}\right) \delta_{\mathrm{c}} 168.2,165.8,159.3,155.4,155.0,138.4$, 126.1, 115.5, 111.6, 62.8, 56.5, 14.3. Anal. calcd for $\mathrm{C}_{14} \mathrm{H}_{13} \mathrm{NO}_{5}$ : C 61.09, H 4.76, N 5.09. Found: C 60.95, H 4.59, N 5.13. HRMS [EI] anal. calcd for 275.0794. Found 275.0797. Crystals of compound $\mathbf{3}$ were grown by vapor diffusion of hexane into a DCM solution. CCDC 904023 contains the supplementary crystallographic data for this paper. These data can be obtained free of charge from The Cambridge Crystallographic Data Centre via www.ccdc.cam.ac.uk/data request/cif.

(Z)-Ethyl 4-[4-(dimethylamino)benzylidene]-5-oxo-4,5-dihydroisoxazole-3-carboxylate (6). Similarly, the use of 4-(dimethylamino)benzaldehyde $(4,0.61 \mathrm{~g}, 4.11 \mathrm{~mol})$ gave the title compound 6 as orange-red needles $(0.22$ g, 19\%). Mp 136-139 ${ }^{\circ} \mathrm{C}$ (decomp.). IR (KBr): $v_{\max } 1739,1720,1566,1541,1522,1506,1380,1185,1177,819$ $\mathrm{cm}^{-1} .{ }^{1} \mathrm{H}$ NMR $\left(500 \mathrm{MHz}, \mathrm{DMSO}-d_{6}\right) \delta_{\mathrm{H}} 8.44(\mathrm{br} \mathrm{s}, 2 \mathrm{H}), 8.23(\mathrm{~s}, 1 \mathrm{H}), 6.91(\mathrm{~d}, J 9.4 \mathrm{~Hz}, 2 \mathrm{H}), 4.39(\mathrm{q}, J 7.1 \mathrm{~Hz}, 2 \mathrm{H})$, $3.20(\mathrm{~s}, 6 \mathrm{H}), 1.34$ (t, J 7.1 Hz, 3H). ${ }^{13} \mathrm{C}$ NMR (126 MHz, DMSO-d 6 ) $\delta_{\mathrm{C}} 169.9,160.1,155.8,155.1,153.3,139.3$, 121.7, 112.7, 104.1, 62.4, 40,3, 14.3. HRMS [EI] Anal. Calcd for $\mathrm{C}_{15} \mathrm{H}_{16} \mathrm{~N}_{2} \mathrm{O}_{4}$ : 288.1110. Found 288.1109.

(Z)-Ethyl 4-[(1H-pyrrol-2-yl)methylene]-5-oxo-4,5-dihydroisoxazole-3-carboxylate (7). Similarly, the use of pyrrole-2-carboxaldehyde $(5,0.39 \mathrm{~g}, 4.11 \mathrm{~mol})$ gave the title compound 7 as orange needles $(0.13 \mathrm{~g}, 14 \%)$. Mp 161-164 ${ }^{\circ} \mathrm{C}$. IR (KBr): $v_{\max } 1743,1720,1575,1549,1521,1282,1173,1087,1022 \mathrm{~cm}^{-1} .{ }^{1} \mathrm{H} \mathrm{NMR}(500 \mathrm{MHz}$, DMSO- $\left.d_{6}\right) \delta_{\mathrm{H}} 12.79(\mathrm{~s}, 1 \mathrm{H}), 8.42-7.50(\mathrm{~m}, 3 \mathrm{H}), 6.68-6.66(\mathrm{~m}, 1 \mathrm{H}), 4.40(\mathrm{q}, J 7.1 \mathrm{~Hz}, 2 \mathrm{H}), 1.35(\mathrm{t}, J 7.1 \mathrm{~Hz}, 3 \mathrm{H}) .{ }^{13} \mathrm{C}$ NMR $\left(126 \mathrm{MHz}, \mathrm{DMSO}-d_{6}\right) \delta_{\mathrm{c}} 172.4,159.8,154.7,138.7,137.6,132.3,131.3,116.2,102.3,62.6,14.3$. Anal. calcd for $\mathrm{C}_{11} \mathrm{H}_{10} \mathrm{~N}_{2} \mathrm{O}_{4}$ : C 56.41, H 4.30, N 11.96. Found: C 56.63, H 4.28, N 11.74. HRMS [El] anal. calcd for: 234.0640, Found 234.0644.

\section{Acknowledgements}

Financial support of our work from the Foundation for Polish Science (Grant number TEAM/2009-4/3) is gratefully acknowledged. 


\section{References}

1. da Silva, A. F.; Fernandes, A. A. G.; Thurow, S.; Stivanin, M. L.; Jurberg, I. D. Synthesis 2018, 50, 2473 and references therein.

https://doi.org/10.1055/s-0036-1589534

2. Vergelli, C.; Schepetkin, I. A.; Crocetti, L.; lacovone, A.; Giovannoni, M. P.; Guerrini, G.; Khlebnikov, A. I.; Ciattini, S.; Ciciani, G.; Quinn, M. T. J. Enzyme Inhib. Med. Chem. 2017, 32, 821.

https://doi.org/10.1080/14756366.2017.1326915

3. Kafle, B.; Aher, N. G.; Khadka, D.; Park, H.; Cho, H. Chem. Asian J. 2011, 6, 2073. https://doi.org/10.1002/asia.201100154

4. Mahajan, S. S.; Scian, M.; Sripathy, S.; Posakony, J.; Lao, U.; Loe, T. K.; Leko, V.; Thalhofer, A.; Schuler, A. D.; Bedalov, A.; Simon, J. A. J. Med. Chem. 2014, 57, 3283.

https://doi.org/10.1021/jm4018064

5. Tang, M.; Odejinmi, S. I.; Allette, Y. M.; Vankayalapati, H.; Lai, K. Bioorg. Med. Chem. 2011, $19,5886$. https://doi.org/10.1016/i.bmc.2011.08.012

6. Becker, T.; Pasteels, J.; Weigel, C.; Dahse, H.- M.; Voigt, K.; Boland, W. Nat. Prod. Rep. 2017, $34,343$. https://doi.org/10.1039/C6NP00122J

7. Parish, C. A.; Smith, S. K.; Calati, K.; Zink, D.; Wilson, K.; Roemer, T.; Jiang, B.; Xu, D.; Bills, G.; Platas, G.; Peláez, F.; Díez, M. T.; Tsou, N.; McKeown, A. E.; Ball, R. G.; Powles, M. A.; Yeung, L.; Liberator, P.; Harris, G. J. Am. Chem. Soc. 2008, 130, 7060.

https://doi.org/10.1021/ja711209p

8. Biju, S.; Gopakumar, N.; Bünzli, J.-C. G.; Scopelliti, R.; Kim, H. K.; Reddy, M. L. P. Inorg. Chem. 2013, 52, 8750.

https://doi.org/10.1021/ic400913f

9. Pérez-Moreno, J.; Zhao, Y.; Clays, K.; Kuzyk, M. G.; Shen, Y.; Qiu, L.; Hao, J.; Guo, K. J. Am. Chem. Soc. 2009, 131, 5084.

https://doi.org/10.1021/ja807394f

10. Poe, A.; Pelle, A. D.; Byrnes, S.; Thayumanavan, S. Chem. - Eur. J. 2015, 21, 7721.

https://doi.org/10.1002/chem.201406625

11. Schiff R.; Betti, M. Chem. Ber. 1897, 30, 1337.

https://doi.org/10.1002/cber.18970300234

12. Minunni, G.; D’Urso, S. Gazz. Chim. Ital. 1928, 58, 485.

13. Donleavy, J. J.; Gilbert, E. E. J. Am. Chem. Soc. 1937, 59, 1072.

https://doi.org/10.1021/ja01285a032

14. De Sarlo, F.; Dini G.; Lacrimini, P. J. Chem. Soc. (C) 1971, 86.

https://doi.org/10.1039/j39710000086

15. Setamdideh, D. J. Serb. Chem. Soc. 2016, 81, 971.

https://doi.org/10.2298/JSC160202050S

16. Rikani, A. B.; Setamdideh, D. Orient. J. Chem. 2016, 32, 1433.

https://doi.org/10.13005/ojc/320317

17. Kiyani, H.; Ghorban, F. Res. Chem. Intermed. 2015, 41, 2653.

https://doi.org/10.1007/s11164-014-1766-7

18. Sun, J.; Wu, Q.; Xia, E.-Y.; Yan, C.-G. Eur. J. Org. Chem. 2011, 2981.

https://doi.org/10.1002/ejoc.201100008 
19. Kato, K.; Yamada, T.; Komamura, T. JP Patent 8095201(A), 1996.

20. Haldar, M. K.; Scott, M. D.; Sule, N.; Srivastava D. K.; Mallik, S. Bioorg. Med. Chem. Lett. 2008, $18,2373$. https://doi.org/10.1016/j.bmcl.2008.02.066

21. Tsien, R. Y. Ann. Rev. Biochem. 1998, 67, 509. https://doi.org/10.1146/annurev.biochem.67.1.509

22. Seres, J.; Daroczi-Csuka, K.; Gall-Istok, K.; Simon, K.; Szilagyi, I. J. Chem. Res. (M), 1995, 1, 244.

23. Yavari, I.; Bayat, M. J. Tetrahedron Lett. 2011, 52, 6649. https://doi.org/10.1016/i.tetlet.2011.10.029

24. Zhang, L.; Wang, X.; Li, S.; Wu. J. Tetrahedron, 2013, 69, 3805. https://doi.org/10.1016/i.tet.2013.05.024

25. del Corte, X.; de Marigorta, E. M.; Palacios, F.; Vicario, J. Molecules 2019, 24, 2951. https://doi.org/10.3390/molecules24162951

26. Meier, H. Angew. Chem. Int. Ed. 2005, 44, 2482. https://doi.org/10.1002/anie.200461146

27. Zhao, Y.; Zhou, N.; Slepkov, A. D.; Ciulei, S. C.; McDonald, R.; Hegmann, F. A.; Tykwinski, R. R. Helv. Chim. Acta 2007, 90, 909. https://doi.org/10.1002/hlca.200790092

28. Beppu, T.; Tomiguchi, K.; Masuhara, A.; Pu, Y.-J.; Katagiri, H. Angew. Chem. Int. Ed. 2015, $54,7332$. https://doi.org/10.1002/anie.201502365

29. Nazir, R.; Meiling, T. T.; Cywiński, P. J.; Gryko, D. T. Asian J. Org. Chem. 2015, 4, 929. https://doi.org/10.1002/ajoc.201500242

30. Fizet, C.; Streith, J. Tetrahedron Lett. 1974, 15, 3187. https://doi.org/10.1016/S0040-4039(01)91857-X 